Note: This is a pre-copy-editing, author-produced PDF of an article accepted for publication in Addiction Research \& Theory following peer review. The definitive publisher-authenticated version [McCambridge J, Conlon P, Keaney F, Wanigaratne S and Strang J (2004) Patterns of alcohol consumption and problems among the Irish in London: A preliminary comparison of pub drinkers in London and Dublin, Addiction Research \& Theory, 12(4), 373-384] is available online at http://www.informaworld.com/smpp/content $\sim \mathrm{db}=\mathrm{all} \sim$ content $=\mathrm{a} 713637856$

\title{
Pattems of alc ohol consumption and problems among the Irish in London: A preliminary comparison of pub drinkers in London and Dublin
}

Published in Addiction Research \& Theory (2004) 12(4), 373-384

J im McCambridge, Paul Conlon, Francis Keaney,

Shamil Wanigaratne, J ohn Strang

\author{
National Addiction Centre \\ (The Maudsley/Institute of Psychiatry) \\ Add ic tion Sc iences Build ing \\ 4 Windsor Walk \\ Denmark Hill \\ London SE5 8AF
}

Correspondence by e-mail: J.McCambrid ge@iop.kcl.ac.uk

\section{Acknowledgements}

The data which enabled this study to be undertaken were orig inally collected during the studentship of the second author (PC) on the MSc in Clinical and Public Health Aspects of the Addictions, University of London. We a re also grateful to the management, staff and participating customers of the four pubs in which this study took place. 


\section{Abstract}

Alcohol related morbidity and mortality rates a mong the Irish in England and Wales are higher than both other ethnic minorities and the general population. Higher consumption per episode of drinking is responsible for higher overall mean consumption levels among the Irish. Pattems of consumption and problemsamong the Irish were investigated in two samples recruited in pubs in London and Dublin. Mean alcohol consumption was found to be higher - by approximately $50 \%$ - in the London sa mple with more high risk d rinking a result of more frequent drinking pattems. Hazardous drinking was strongly nomative among young Irish people in both London and Dublin. The distinct Irish style of drinking - grea ter quantities per episode and the English pattem of more frequent drinking combine to produce elevated risk among the Irish in London. Irish drinking pattems in general, and the alc ohol related needs of the young Irish in Brita in in particular, require further study to better understand the nature of risk and to prevent ham. 


\section{Introduction}

Alcohol Consumption \& Problems a mong the Irish in Brita in

Alcohol-related mortality in England \& Wales among those bom in Ireland is substantially higher - both by comparison with other ethnic minorities and with the general population (Ha mison, Sutton \& Gardiner, 1997). General and psychia tric hospital a dmissions data also provide evidence of elevated alcohol-related morbidity (Cochrane, 1977; Cochrane \& Bal, 1979; Dean, Downing \& Shelley, 1981; Taylor et al., 1986; Commander et al., 1999; Canning et al., 1999).

These pattems of differential morbid ity and mortality can be seen to have a relationship to some measures of elevated consumption in nationally representative survey data. The Health Survey for England in 1999 compared the health of the Irish with five other ethnic minorities and with the general population (http://archive.official-documents.co.uk/document/doh/survey99). This survey found that all other ethnic minorities were less likely to drink alc ohol, drank less frequently and consumed smaller a mounts than the general population. By contrast, the Irish were either found to be similar to the general population or to be at higher risk. Whilst having similar frequencies of drinking, greater a mounts of alc ohol consumed per episo de of drinking a re largely responsible for higher mean consumption levels among the Irish in Brita in. 
Although not specific a lly rela ted to alc ohol consumption, health inequalities in the form of elevated mortality rates have been found to extend into second and third generation Irish in Brita in (Harding \& Bala rajan, 1996; Harding \& Balarajan, 2001). These health inequalities reflect, but are not solely explained by, socio-economic inequalities experienced by the Irish (Wild \& McKeigue, 1997; Hickman \& Walter, 1997; Abbots et al., 2001).

Various explanations have been offered for these data. Greenslade, Pearson \& Madden (1995) argue that the influence of stereotypical views of Irish drinking pattems has inhibited serious research and policy attention to this area, in Ireland as well as elsewhere. Cochrane (1977) identifies three hypotheses drawn from wider work on the mental health of migrant populations, which may expla in higher levels of drinking problems. These direct attention to (1) levels of alc ohol consumption and problems in Ireland (hypothesised rates higher than the host country), (2) the process of migration itself (hypothesised to promote alcohol involvement), and (3) the characteristic sof the migrants themselves (migrant selection hypothesis).

Studies of drinking a mong migrant lrish populations have been undertaken since the 1940s. For example, Stivers (1976) describes the ways in which spec ific 'hard-drinking' characteristic s of the Irish combined with the initia lly hostile stereotypical view held by Americ a n soc iety of the 'ha bitual drunkard' to produce a convergent positive and accepted identity of the 'happy 
drunk'. This acceptance of Irish drinking practices in the U.S. was associated with broader social inclusion and access to political power.

Abbots et al. (2001) observe that continuing socio-economic disa dvantage among Irish migrants in Brita in contrasts sharply with the U.S.A., and propose that attention needs to be drawn to particular national contexts. Hic kman \& Walter (1997) identify pervasive ongoing anti-lrish discrimination throughout British society, and Ha mison et al. (1997) suggest that the racism experienced by the Irish in Brita in may be responsible for elevated levels of alcohol-related morta lity.

Comparisons of Alc ohol Consumption \& Problems in Ireland \& Britain Levels of alc ohol consumption in Ireland have increased rapidly over the last fifteen years, during which time Ireland has become the fastest growing economy in Europe. Percapita consumption was equivalent to that of Brita in in 1989, at 7.6 litres of pure alcohol in both countries. Whilst Brita in was one of the few countries in the European Union (E.U.) in which percapita consumption increased between 1989 - 2000 (to 8.4 litres), this increase was dwarfed by the increase in Ireland to 11.1 litres over the same period (Strategic Task Force on Alcohol Interim Report, 2002). Ireland, from being the second lowest in the E.U. in 1989, had the second highest rate of percapita alcohol consumption in the E.U. by the year 2000 (Strategic Task Force on Alc ohol Interim Report, 2002). 
Comparisons of general population data between the two countries (regular General Household Survey in Brita in and specially commissioned survey in Ireland in 1999) reveal broad simila rities in consumption pattems (Friel, Nic Gabha inn \& Kelleher, 1999; Walker et al., 2001; Strategic Ta sk Force on Alc ohol Interim Report, 2002). For example, in both countries younger people are more likely to drink higher quantities per occasion of consumption and for there to be similar pattems among both young women and men. Olderage groups, on the other hand, are more likely to be more frequent drinkers at lower qua ntities of consumption, with men drinking more heavily than women, in both countries.

Ha mison, Ca r-Hill \& Sutton (1993) found a higher proportion of men reporting two or more physical or psychological problems resulting from alcohol consumption in Ireland compared to England \& Wales in data collected during the 1980s. O'Connor (1978) examined pattems of consumption, attitudesand problemsamong young people in Ireland and England, including among second-generation Irish i.e. those bom in England of parents bom in Ireland. This group (along with their parents) were found to be substantially heavier drinkers than either the Irish (in Ireland) or the English. Detailed comparisons of pattems of consumption and problems between the two countries a re otherwise limited.

Cross-national comparisons between Brita in and Ireland a re evidently subject to substantial influence by change over time, and a re characterised broadly 
by simila rity in patteming. Any contribution of the first hypothesis advanced by Cochrane (hypothesised rates higher than the host country) is thus thought to be both diffic ult to evaluate, but likely to be modest.

Other Possible Explanations for Elevated Consumption \& Problems among the Irish in Britain

Harrison \& Carr-Hill (1992), in an investigation of the Irish in England, found that majorities of both men and women with alcohol-related problems reported the onset of these problemsas occuming after migration. The migration strain hypothesis (2) and the migrant selection hypothesis (3) may both be investigated by examining the drinking pattems and psychosocial characteristic s of migrants with comparable non-migrants. Deta iled comparison of pattems of consumption and problems between the Irish in Brita in and those remaining in Ireland are unknown to the authors. The basic rationale for making such comparisons may be summarised as having the potential to increase understanding of the distinct alcohol-related needs of the Irish in Brita in i.e. those arising out of migration to and living in Brita in, thereby permitting consideration of the second and third hypotheses identified by Cochrane - migration as a source of increased risk and high-risk people being more likely to migrate.

In the absence of prior study, it was decided to conduct a preliminary investigation of pattems of consumption and problems between the Irish in the two countries. In addition to this main foc us of the study, it was decided 
also to consider the extent to which the views of the Irish migrants rela ting to alcohol were similar to those held by non-migrants. It may be that acculturation leads the migrant to view alcohol in a way distinct from that held by the non-migrant, and that these views have implic ations for pattems of consumption and problems including definitions of problem drinking. These preliminary investigations are necessarily conducted for the purpose of more detailed hypothesis generation.

\section{Methods}

Sampling, Setting \& Participants

A non-probability sampling method was used. A probabilistic sampling strategy, providing in many ways the most appropriate means of making intended comparisons, was precluded on grounds of cost and time available in which to undertake the study. Additionally, we specifically wished to oversample heavier drinkers, in order to explore in depth the relationships between pattems of consumption, and different types of risk and problems in the two countries. To this end, we recruited convenience samples in two locations - two pubs each in London and Dublin, matched on a number of variables. London and Dublin were deemed to be urban locations as equiva lent as possible in the circ umstances of the study.

This sampling method is biased in the way required, with heavier pub consumers, by definition, spending more time on licensed premises than lighter consumers. It was understood at the outset that this sampling method 
excluded those populations with most severe and complexalcohol problems, by virtue of their exc lusion from this setting. Street drinkers in both cities, including those who are chronic ally intoxicated, or who may be homeless, or have signific ant dual diagnoses involving alcohol, were understood to be less likely to be found in pubsfor a va rety of reasons. In some respects, exclusion from pubs may be one component of their broader social exclusion.

Pubs have previously been used as settings for ethnographic and other qua lita tive studies of drinking pattems and consequences. Epidemiologic al or other quantita tive studies that have opportunistic a lly sampled pub drinkers are rare and have usually been concemed with the pub itself as a risk environment (see Miller \& Williams, 1981 for example). Pubs are self-evidently settings in which large numbers of drinkers may be recruited quickly. They potentially offer a low cost, easy to access, setting in which quantita tive alcohol data may be rapidly collected. Satisfactory procedures are needed to ensure that intoxication does not undemine the reliability of data obtained.

Opportunistic sampling of targeted drinking populations has been previously used to explore in-depth pattems of consumption and risk (see for example Hamett et al., 1999). Whilst there may be inherent problems in detemining the representativeness of pub samples, these a re certa inly not insumountable. For example, it may be possible to collect data on socio demographic, drinking and other characteristics in order to compare 
with available local or general population data (as was done by Cosper, Okraku \& Neumann, 1988).

In the present study, cross-national comparison was identified as being the primary object of interest. This study was thus designed to rec ruit equiva lent populations, with identical procedures being used in each location. The potential exists, however, for hidden sa mpling bias, undermining the validity of the comparison, and this may be diffic ult to evaluate. Therefore, given the limitations of the sampling method, post-hoc consideration of unantic ipated sourc es of sampling bias in respect of the achieved sample is needed, and will precede any consideration of the generalisability of the findings.

Study participants were rec ruited from two well-known pubs on the Holloway Road in north London and two equivalents on Dorset Street in north Dublin. This area of London has a longstanding reputation for having a large Irish population. These locations were also selected on the basis of similarities in proximities to; city centres; retail and shopping facilities; educational establishments; major hospitals; and having a mix of social housing, owner occupied and private rented property in each area (Conlon, 2001). All four establishments were also understood to have a wide range of customers, and to be reasonably busy throughout the day: - which matched the time ava ila ble for field work in circ umstances most conducive to reliable data collection. 
Partic ipants were required to be Irish (i.e. bom on the island of Ireland), over eighteen years old, resident in either Dublin or London for more than one year, never to have attended a treatment agency in relation to their alc ohol use and to have literacy suffic ient for questionnaire completion. Additionally, prior to approach as soon as possible after entry to the pub, partic ipants were informally assessed for signs of prior intoxic ation, and potential study partic ipants who were judged already to be intoxic ated were not approached.

Data Collection \& Measures

The second a uthor (PC) attended both sites in Dublin and both sites in London at different times of the day and on all days of the week. A typical field session averaged four hours in duration. Data wascollected from the Dublin sample first, over a 12-day period. Data collection from the London sa mple took 15 days to complete, with all data collection in both cities taking place in the month of J uly 2001.

Potential partic ipants who appeared to meet study criteria were approached shortly after they entered the pub. Written consent was obtained following invitation to participate in the study and the asking of sc reening questions. Partic ipants were given both verbal and written information about the study. No information involving personal identific ation was requested and appropriate assurances of confidentiality were given. A self-completion questionna ire was used, which took approxima tely 20 
minutes, a fter which time the completed questionnaire wascollected by the researcher.

A data collection target of 140 questionnaires was set - 70 each for Dublin and London. In Dublin, 76 questionnaires were initially collected, with 12 refusals. In London, 65 were completed with 5 refusals. A total of 10 questionna ires were later excluded for reasons of ina dequate completion or information indicating ineligib ility. This resulted in a total sample size of 131 partic ipants, comprising 70 from Dublin and 61 from London.

In addition to sociodemographic data, partic ipants were invited to categ onize their current drinking pattem by frequency and to describe their drinking over the previous week and month. Data were collected on both the quantities and types of alc ohol, as well as the context of drinking.

Two distinct standardised self-report mea sures of alc ohol-related problems were also incorporated. The first of these mea sures hazardous d rinking, comprised of components of consumption, problems and dependence (the Alc ohol Use Disorder Identification Test [AUDIT]; Babor et al., 1992). The second measure used was a dedicated measure of dependence, specific ally developed to be sensitive to dependence in non-treatment populations (Short Alcohol Dependence Data [SADD]; Davidson \& Raistrick, 1986). 
In addition to these consumption and problems data, partic ipants were asked if they had experienced any of a listed series of consequences of drinking over the last year. They were also a sked for their views on whether a series of alc ohol-related negative consequences constituted a problem, and whether they believed these consequences were suffic ient reasons for personal behaviour change.

Expectancies have proven to be predictive of consumption pattems in adults (Lee, G reely \& Oei, 1999) and to be variable cross-cultura lly, with distinctly Irish pattems having previously been described in a treatment population (Teahan, 1998). Expectancies, as manifestations of Irish cultural beliefs a bout alcohol, were measured using the Drinking Expectancy Questionnaire (Young \& Knight, 1988). This instrument yields a total sc ore and six sub-sc ale scores representing assertiveness, negative affective change, dependence, sexual enhancement, cognitive enhancement and tension reduction respectively.

\section{Data Analyses}

In addition to the presentation of data straightforwardly comparing London and Dublin, a series of multiple regression analyses were undertaken to examine whether any univariate relationships between London/Dublin location and consumption and problem variableswere robust to potential confound ing by othervariables. These a nalyses all considered the following varia bles as potential confounders: age, sex, relationship sta tus (single/nonsingle), educational atta inment (higher education or not), a ny fa mily a lc ohol 
problem history (yes/no) and total expectancy score. Stepwise backward elimination procedures were employed with a criterion of $p=0.1$. All a nalyses were performed using SPSS Version 11.

\section{Results}

The Sample

The overall sample comprised 75 (57\%) males and 56 (43\%) females. The mean age of the total sample was 32 years, with the youngest participant being 18 years old and the oldest 65 years old. Fifty-eight people (42\%) reported being mamied or cohabiting, 12 (9\%) being divorced or separated and the remainder $(n=64,49 \%)$ of the sample reported being single. The majority ( $n=72,59 \%)$ had atta ined some form of higher education qualific ation ranging from diploma through to postgraduate degree. Only 3 (2\%) ind ividuals reported being unemployed, 10 (8\%) were students and the remainder were in part or full-time employment.

Table 1: Basic Sociodemographic Charac teristic s of London \& Dublin Samples

\begin{tabular}{|lll|}
\hline & London & Dublin \\
Mean Age (in years) & 36 & 30 \\
\%Female Gender & 41 & 44 \\
\% Single* & 56 & 61 \\
\%Higher Education & 64 & 47 \\
\%Current Employment & 96 & 90 \\
\% Family History of Alc ohol Problems & 48 & 48 \\
*incl. separated/divorced/widowed & & \\
\hline
\end{tabular}


The London and Dublin samples are compared in Table 1. There wasone statistic ally signific ant difference between the samples rec ruited in London and Dublin: The London sample was older (see Table $1 ; t=3.99, p \varangle 0.001$ ). The London sample was also more likely to have a higher education qualific ation (see Table 1), though this wa s not statistic a lly signific ant (chi-sq. $=3.7,2 \mathrm{df}$, $p=0.054)$.

\section{Alcohol Consumption Pattems}

In the week prior to data collection, mean alcohol consumption level was 63 units in the London sample (SD=42), compared to 43 units in Dublin $(S D=30$, $t=2.98, p=0.01$ ). A similar difference was observed in the previous month, with the mean number of days on which alc ohol wasconsumed being 14 days in Dublin (SD=7), compared to 20 days in London (SD=8, $t=4.26, p=0.001$ ). However, in a typical day drinking in the previous month, the two samples were very similar in quantity consumed -13.3 units in Dublin $(S D=5.7)$ and 13.1 units in London ( $S D=5.5)$. Also there was no signific ant difference in the number of times partic ipants reported being drunk in the previous month - 6 times in Dublin $(S D=6.5)$ and 8 times in London $(S D=6.5)$ respectively. Table 2 presents data on how partic ipants categorised their current consumption pattem by frequency of drinking. These categorical differences in drinking frequency were also statistic ally signific a nt (Linear chi.sq $=24.7,3 \mathrm{df}, \mathrm{p} \varangle 0.001$ ). 
Table 2: Current Drinking Frequency Categories

\begin{tabular}{|lccl|}
\hline Drinking Frequency & Dublin & London & Total \\
Less than weekly & $10(14 \%)$ & $1(2 \%)$ & $11(8 \%)$ \\
$1-3$ times weekly & $41(59 \%)$ & $20(33 \%)$ & $61(47 \%)$ \\
$4-6$ times weekly & $18(26 \%)$ & $29(48 \%)$ & $47(36 \%)$ \\
Daily & $1(1 \%)$ & $11(18 \%)$ & $12(9 \%)$ \\
Total & $70(100 \%)$ & $61(100 \%)$ & $131(100 \%)$ \\
\hline
\end{tabular}

Finally, in respect of consumption level, participants were categorised as being low, medium and high consumption according to whether they exceeded previously recommended weekly thresholds of 21 units and 50 units for men, and 14 units and 35 units for women respec tively in the previous week (1 unit being a half-pint of ordinary strength beer). Sixty-four percent of the London sample were categorised as high consumption, compared to $43 \%$ of the Dublin sample. Twenty-one percent of the Dublin sample fell into the low consumption category, wherea s only $5 \%$ of the London sample fell into this low consumption category (Linear chi-sq $=8.0,1 \mathrm{df}, p=0.004$ ).

Are London-Dublin Consumption Differences Explained by Associations With Other Variables?

Each of the four consumption va riables (number of days drinking, number of times drunk and quantity consumed perdrinking day all in the previous month, and amount consumed in the previous week) was separately 
considered in multiple regression analyses to examine the robustness of any London-Dublin differences. In addition to location ( $B=0.34, p \varangle 0.001$ ), only gender ( $B=0.24, p=0.004)$ was associated with frequency of drinking in the previous month. After controlling for the influence of gender, those in London were drinking on 5.5 days more in the past month than those in Dublin.

There was no London-Dublin difference in quantity consumed per drinking day in the previous month, with only gender $(B=0.39, p<0.001)$ and expectancies $(B=0.24, p=0.018)$ being associated with this va riable. Although the London-Dublin difference was not signific ant in the univaria te a nalysis of number of times drunk in the previous month (see previous section), this difference did become signific ant in the multivaria te a nalysis, partly as a result of the influence of age, which was non-equivalent in the two samples. In addition to location ( $B=0.20, p=0.029)$ and age $(B=0.29, p=0.002)$, gender $(B=0.26, p=0.004)$ and expectancies $(B=0.19, p=0.029)$ were also associated with frequency of being drunk.

The difference in total consumption in the previous week between London and Dublin a Iso remained signific ant $(B=0.25, p=0.003)$. The mean consumption level in the London sample was approximately 19 units higher than the Dublin sample after controlling forgender $(B=0.31, p \varangle 0.001)$ and expectancies $(B=0.16, p=0.06)$. 
Expectancies \& Other Views on Alcohol

There were no differences between the London and Dublin samples in expectancies, neither in total sc ores nor subsc a le-sc ores for a ssertiveness, nega tive affective change, dependence, sexual enhancement, cognitive enhancement and tension reduction respectively (a ll $p>0.1$ ). Of 32 negative consequences, on six items there were statistic ally sig nific ant differences between the London and Dublin samples as to whether the consequence constituted a problem.

The London sample were more likely to see having a hangover (chi-sq. $=5.5,1$ df, $p=0.019$ ), vomiting (chi-sq. $=6.2,1 \mathrm{df}, p=0.013$ ) and dia mhoea (chi-sq $=8.3,1$ $d f, p=0.004)$ as problematic. The Dublin sa mple were more likely to see drinking in the moming (chi-sq. $=5.3,1 \mathrm{df}, \mathrm{p}=0.022$ ), drinking every day (chi$s q .=10.9,1 \mathrm{df}, \mathrm{p}=0.001$ ) and spending most of leisure time drinking (chi$s q .=7.0,1 \mathrm{df}, p=0.008$ ) as being problematic. When controlling for consumption using the previous week measure in logistic regressions, only this last difference remained statistic ally significant.

Partic ipants were also a sked whether they thought the 32 negative consequences provided suffic ient reasons to change their drinking behaviour. On only one item - alc ohol having an adverse effect on your health - was there a signific ant difference between the two sa mples, with those in London more likely to cite this as a reason to change drinking ( $86 \%$ 
compared to $56 \%$, chi-sq. $=12.9,1 \mathrm{df}, \mathrm{p} \varangle 0.001$ ). This difference rema ined signific ant after controlling for past week consumption.

\section{Alcohol Problems}

Partic ipants were invited to report on how often they had experienced each of 20 nega tive consequences of drinking over the last year. These consequences were described as effects rather than problems. There were no differences between the London and Dublin samples on any item. Similar proportions of the samples in London (80\%) and Dublin (73\%) exceeded the AUDIT threshold for hazardous drinking (sc ore of eight; Conigrave, Hall \& Sa unders, 1995). Mean AUDITscores were also similar - 11.3 in Dublin and 12.5 in London. Similarly with SADD scores, $25 \%$ of the Dublin sample and $28 \%$ of the London sample exceeded a threshold score of 10 , indic ating moderate dependence, with mean scores being 6.1 for Dublin and 6.9 for London respectively. None of these differences were statistic ally signific ant in these univa ria te a nalyses (all $p>0.1$ ).

In the multivariate analyses, a statistic a lly signific ant difference in mean AUDIT scores between the London and Dublin samples was identified and is reported in Table 3. No London-Dublin differences in mean SADD dependence scoreswere detected. 
Table 3: Variables Associated with Hazardous Drinking (Mean AUDITScores)

\begin{tabular}{|lll|}
\hline & Beta Values & P - Values \\
London location & 0.19 & 0.012 \\
Youngerage & 0.27 & 0.001 \\
Male gender & 0.22 & 0.003 \\
No highereducation & 0.13 & 0.069 \\
Expectancy score & 0.56 & $\varangle 0.001$ \\
\hline
\end{tabular}

Other Variables of Interest

The presentation of results has given most prominence to the central variable under study - differences between the London and Dublin samples. A brief note will be made here of other findings in the preceding a nalyses. In every instance, gender was identified as being associated with the consumption and problem variables modelled in the multiple regression analyses, with male gender being indic ative of heightened risk. For both consumption and haza rd ous drinking, expectancies favouning alc ohol consumption, and youngerage are also found to be associated with elevated risk. Youngerage was also found to be associated with elevated SADD score and with greater reported frequency of being drunk in the month prior to data collection.

\section{Disc ussion}

In this targeted sample of pub-drinkers in London \& Dublin, Irish people in London were found to consume more alcohol than their counterparts in Dublin, with this difference being almost entirely as a result of more frequent 
drinking pattems - approximately $50 \%$ higher on two different measures. The difference remains statistic ally significant, and the magnitude of the difference similar, after controlling for other possible factors such as age and gender.

How valid are the comparisons that have been undertaken in light of the limitations of the sampling strategy and thus how generalisable are these findings? In the relatively small number of va ria bles available for assessment of underlying population differences, non-equivalence in age and to a lesser extent higher education was identified. The small sa mple size entails that differences between the two populations would need to be large to be detected. It would indeed appear plausible that there are other unmeasured differences that will have implic ations for comparisons between the two populations. The limitations of the sampling method have thus yielded samples for which caution in making population inferences is a ppropriate.

Taking account of what is known from other sources, a long with some striking simila rities in a lc ohol-specific data, these small samples do however exhibit characteristic s which are of interest. National survey data (Health Survey for England, 1999) demonstrate that the Irish in England are similar to the general population in respect of frequency of drinking and that it is quantity per episode that differentiates the Irish from the general population. In the London sample, it appears that the Irish have acquired the English pattem of frequency of d rinking, whilst reta ining the Irish pattem of quantity of 
consumption. There is a similarly high rate of reported pa rental history of alcohol problems in both samples.

One possible explanation for increase in frequency rather than quantity of drinking might be an increase in disposable income - this has previously been observed in the Shetland Islands following the oil boom (Caetano et al., 1983) and among Mexican migrants to the U.S. (Caetano \& Medina-Mora, 1988). This possibility highlights a further limitation of this study: - the lack of inclusion of an income measure. G reater levels of Higher Education in the London sample may be indicative of greater affluence. Altematively, there may be some mechanism of acculturation in the adoption of more frequent drinking. There is a Iso potentially a double-edged nature of the Irish pub in England providing both a sense of community and engendering alc ohol-related risk. It has also been found that ma inta ining links with home and a rela tive lack of integration into British society may be protective in relation to alcohol risk (McNicholl, 1992).

Apart from these differences, va rious simila rities between the two samples are partic ula lly noteworthy. Quantity consumed per episode of drinking is very similar in the two samples, as are alcohol-related expectanciesand a wide range of views on alc ohol consumption, risks and problems. The Irish in Brita in have thus not acquired different British opinions on alc ohol. 
Not only are heavier drinkers to be found straightforwardly in pubs in both London and Dublin, but so too a re young people with a lready existing alcohol-related problems. It would appearfrom the AUDITdata that ha za rd ous drinking is strongly no mative among young Irish people, both in London and Dublin, and potentia lly elsewhere too. Concems a bout d rinking among the young have been established in Ireland (Department of Health \& Children, 2002), but research attention has not previously been drawn to pattems of youthful drinking among the Irish in Brita in. The existing literature is primarily focused on the physical and mental health problems consequent on long-term chronic excessive alcohol consumption, and in partic ular on the sub-population with multiple and severe problems. The logic of earlier intervention is all the more compelling in circ umstances in which problems and dependence are already evident among many young people.

Similarities in some a spects of a lcohol risk, a long with grea ter levels of partic ipation in higher education in the London sample are suggestive that the migrants in this sample are not more psychosocially or socioeconomic ally at risk than their non-migrant counterparts (hypothesis 3). The lack of more detailed data on psychosocial risk characteristic s prevents further examination of the migrant selection hypothesis in this sample, and points to the need for further study. Identified differences in pattems of consumption and problems between the two samples, subject to appropriate methodologic al qualification, may thus be interpreted as supportive of 
further investigation of hypothesis 2 - a rising from the process of migration to (and experience in) England.

This preliminary investigation thus yields more detailed targets for further research investigations. It may be helpful to pursue methodological consideration of pubs as settings for opportunistic sa mpling of distinct drinking populations. Further data representative of the Irish in England are needed to explain how and why drinking frequency is elevated in England. What is there in the nature of the experience of being Irish in England that leads to the apparent continuation of some aspects of Irish d rinking practic es but not others? It would appear that the alcohol-related needs of the young Irish in Brita in have been overlooked. The existence of distinct Irish styles of drinking involving greater quantities of consumption perepisode also requires further study, having implic ations for interventions in both Brita in and Ireland. 


\section{References}

AbbotsJ Williams R Ford G (2001) Morbid ity and Irish catholic descent in Brita in: Relating health disadvantage to socio-economic position. Social Science \& Medic ine 52: 99-1005

BaborTF Ramon de la Fuente J Saunders J Grant M (1992) The Alcohol Use Diso rders Identification Test: Guidelines for use in Primary Health Care. World Hea Ith Organisation

Caetano R Medina-Mora ME (1988) Acculturation and drinking among people of Mexican descent in Mexico and the United States. J oumal of Studies on Alc ohol 49: 462-471

Caetano R Suzman RM Rosen DH Voorhees-Rosen DJ (1983) Shetland Island: Longitud inal changes in a lcohol consumption in a changing environment. British Joumal of Addiction 78: 21-36

Canning UP Kennell-Webb SA Marshall EJ Wessely SC Peters TJ (1999) Substance misuse in a cute medical admissions. Quarterly J oumal of Medic ine 92: 319-26.

Cochrane R (1977) Mental illness in immigrants to England and Wa les: an a na lysis of mental hospital a d missions 1971. Social Psychiatry 12: 25-35

Cochrane R \& Bal SS (1989) Mental health a dmission ra tes of immigrants to England: a comparison of 1971 and 1981. Social Psychiatry and Epidemiology 24: 2-11.

CommanderMJ Odell S Sashidharan SP Surtees PG (1999) Psychiatric morbidity in people bom in Ireland. Social Psychiatry and Psychiatric Epidemiology 34: 565-69.

Conigrave KM Hall WD Saunders J (1995) The AUDITquestionna ire: choosing a cut-off sc ore. Addiction. 90:1349-56

Conlon P (2001) A comparative ana lysis of drinking pattems between two non-treatment populations in Dublin and London. MSC in Clinic al and Public Health Aspects of the Addic tions, University of London

Cosper RL Okraku IO \& Neumann B (1988) A national survey of regulars at public drinking establishments. J oumal of Studies on Alc ohol 48: 252-259

Davidson R \& Ra istrick D (1986) The valid ity of the Short Alcohol Dependence Data (SADD) questionna ire: A short self-report questionnaire for the assessment of alc ohol dependence. British Jo umal of Addic tion 81: 217-222. 
Dean, G., Downing, H. \& Shelley, E. (1981) First admissions to psychiatric hospitals in south-east England in 1976 a mong immigrants from Ireland. British Medical Joumal 282: 1831-1833.

Friel S Nic Gabhainn S Kelleher C (1999) The National Health and Lifestyle Surveys Health Promotion Unit, Department of Health and Children, Dublin.

Greenslade, L Pearson \& Madden (1995) A good man's fault: alcohol and Irish people living abroad. Alc ohol and Alcoholism: pp407-417 vol.30, no.4.

Harding S \& Balarajan R (1996) Pattems of mortality in second generation Irish living in England and wales: Longitudinal study British Medical Joumal, 312:1389-1392.

Harding, S., and Balarajan, R. (2001) Mortality of third generation Irish people living in England and Wales: longitudinal study. British Medical Joumal 332:466-467.

Hamett, R., Heming, R., Thom, B., and Kelly, M. (1999) Exploring Young Mens Drinking Using the AUDITQ uestionnaire. Alc ohol and Alc oholism Vol. 34, No 5, pp. 672-677

Ha mison L \& Carr-Hill R (1992) Alc ohol and Disa dvantage a mongst the Irish in England London, Federation of Irish Societies

Ha mison, L., Carr-Hill, R. \& Sutton, M. (1993) 'Consumption and ha m: drinking pattems of the Irish, the English and the Irish in England' Alcohol and Alcoholism, 28(6): 715-23.

Hamison L. Sutton M. Gardiner E. (1997) Ethnic differences in substance use and alcohol-use-related mortality a mong first generation migrants to England and Wales. Substance Use \& Misuse 32(7-8):849-76

Hea lth Survey for England (1999) http://a rchive.offic ial-documents.co.uk $\angle$ document/doh/survey99

Hic kman MJ \& Walter B (1997) Discrimination and the Irish Community in Britain London, Commission for Racial Equality

Lee, N., Greely, J ., and Oei, T. (1999) The relationship of positive and negative alcohol expectancies to pattems of consumption of alcohol in social drinkers. Addictive Behaviours, Vol. 24. No. 3. pp 359-369

McNicholl D (1992) The extent of problematic drinking among the Irish population in England and associated migration factors. New Directions in the Study of Alc ohol 18: 29-40 
Miller KD \& Williams AF (1981) Blood a lc ohol concentrations of patrons leaving a collge pub. Joumal of Studies on Alcohol 42: 676-679

O'C onnorJ (1978) The Young Drinkers: A Cross-National Study of Social and Cultural Influences. London, Tavistock

Stivers R (1976) A Hair of the Dog: Irish Drinking and American Stereotype. London, Pennsylvania State University Press

Strategic Task Force on Alcohol Interim Report (2002) Dublin, Department of Hea Ith and Children

Taylor CL Passmore N Kilbane P Davies R (1986) Prospective study of alc ohol-related admissions in an inner-city hospital. Lancet 2: 265-268

Teahan,J.E.(1998). Alcohol expectancies of Irish and Canadian Alcoholics. The Intemational J oumal of Add ic tion, 23 (10),1057-1070

Wild S\& McKeigue P (1997) Cross sectional a nalysis of morta lity by country of birth in England and Wales, 1970-92. British Medical Joumal 314: 705-710

Young, R, McD. and Knight, R,G. (1988) The drinking expectancy questionnaire: A revised measure of alc ohol-related beliefs. J oumal of psychopathology and behavioral assessment, vol. 11, no 1 